\title{
ROLE OF ILLUSION OF CONTROL BIAS IN HERDING BEHAVIOUR
}

\author{
*Mary Metilda J
}

\begin{abstract}
Herding is a behavior that follows the decision of the majority and is described as an imitation behavior resulting from individual factors and often leading to inefficient outcomes for the market as a whole. Information assymetry plays a major role in herding and so does other behavioural biases. Illusion of Control is one such bias which leads to excess trading and decreased returns. This research aims to analyse the relationship between the Illusion of Control Bias and Herding Mentality among mutual fund investors. To test the above relationship, data was collected from a sample of 309 Mutual Fund Investors. The data was analysed using Pearson's Correlation and regression analysis. The findings of the study indicate that there is a positive association between the two biases and Illusion of Control Bias is a significant predictor of the dependent variable Herding.
\end{abstract}

Keywords: Herding, Illusion of Control, Investor Bias, Mutual Fund Investor

\section{INTRODUCTION}

The efficient market hypothesis assumes that information is freely available to all and that investors interpret the information in the most rational way. This rational approach in finance is time and again put to test with the broader approach from behavioural finance where its proponents believe that numerous factors both rational and irrational thinking drive investor behaviour. According to Hirshleifer (2001), expected returns are determined by risk and misevaluation. DeBondt et al. (2008) studies find that the investment decision process has a) A catalog of biases b) Investor sentiment matters and c) Decision processes shape decision outcomes. The financial market is loaded with information assymetry and sometimes investors opt for imitation to cope with the informational limitations in the markets. When many of such investors imitate at the same time herding appears. Herding is influenced by various factors including individual cognitive biases. This paper is a study focusing on the influence of Illusion of Control Bias and Herding Behaviour. The first section of this paper gives the background to the study with the review of the earlier studies. This is followed by the methodology and data anaysis /results. The final section summarises the findings of the study and concludes discussing the scope for further studies.

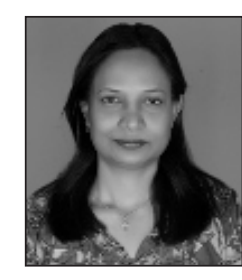

\section{*Dr. Mary Metilda J}

Bangalore 


\subsection{HERDING}

Herding is a behavior that follows the decision of the majority rather than relying on rational thinking (Sheriff 1996). It is described as an imitation behavior resulting from individual factors and often leading to inefficient outcomes for the market as a whole. This behavior of investors might feed speculative investment bubbles, which would lead to substantial welfare losses when these bubbles burst. Motives for herding are three according to Bikchandani \& Sharma (2000) i.e. information based herding, reputation based herding and compensation based herding.

Information based herding occurs when analysts lack confidence above their private information and there exists uncertainty about the quality of public information. As a consequence, investors abandon their private signal and follow the herd which may lead to suboptimal results. In reputation based herding (Scharfstein \& Stein (1990) and Trueman (1994), analysts manipulate forecasts to get closer to the majority so that their information is correlated with their peers.

Thirdly, compensation herding can also arise as a consequence of payoff externalities (Maug \& Naik (1996) and Chevalier \& Ellison (1997). This kind of herding is to avoid penalization due to bad forecasting. That is cited as the reason for inexperienced analyst to herd more than experienced analyst. Research shows a negative relationship between degree of herding and analyst experience (Krishnan et.al.2006)

Studies of Taquadus Bhashir et al (2014) shows that information uncertainty and investors cognitive profile lead to herding. So, investors' decisions are surrounded by uncertainty, because of the informational limitations in the markets and also because of individuals' cognitive limitations. Evidence shows the influence of numerous cognitive biases in investor decision making. Some biases show to favour herding like the overconfidence bias and illusion of control bias. Studies of Beatriz Fernandiz et al (2001) show that illusion of control bias favours herding. According to Langner, Individuals suffering from the illusion of control bias think they can control and influence totally random events, underestimate the role of chance and perceive games of chance as games of skill (Langer, 1975; Kahneman and Riepe, 1998). Under uncertainity of outcomes, such individuals assume that other investors have taken decision based on relavant information and imitate their investment and consequently, the illusion of control encourages herding.

\subsection{ILLUSION OF CONTROL BIAS}

Illusion of Control bias is a tendency in human beings which leads to believing that they can control or atleast influence outcomes, when in fact they cannot. It is the expectancy of a personal success probability inappropriately higher than the objective probability would warrant (Ellen langer). Langer found that choice, task familiarity, competition and active involvement can all influence confidence and generate such illusions. He observed that people who were allowed to select their own numbers in a hypothetical lottery game were also willing to pay a higher price per ticket than subjects gambling on randomly assigned numbers. Gerlinde Fellner (2004), in her paper 'Illusion of Control as a source of Poor Diversification: An 
Experimental Approach', investigating factors influencing individual portfolio allocations found that her subjects were prone to illusion of control and the effect vanishes with experience. Amongst other implications to investors like trading more than is prudent and holding underdiversified portfolios, Illusion of Control bias encourages herding behaviour. Studies show the influence of gender (Eagly \& Carli (1981), experience (Prendergast \& Stole (1996), Avery \& Chavelier (1999) and investment time horizon, (Suto \& Toshino (2004), as some of the factors influencing herding. As most studies do talk of the influence of demographic varibles on herding bias, This study aims at analysing the relationship between Illusion of Control Bias and Herding Behaviour and attempts to answer the following research questions.

1) Are the mutual fund investors influenced by Illusion of control Bias and Herding Bias fl

2) Is there a positive association between the two biases fll and

3) Is Illusion of Control Bias a significant predictor of Herding Bias $\mathrm{fl}$

To answer the above questions, the following hypothesis is tested.

H1: There is a significant relationship between Illusion of Control Bias and Herding Bias

$\mathrm{H} 2$ : Illusion of Control Bias is a significant predictor of Herding Bias

\section{METHODOLOGY}

The study uses deductive logic reasoning and a survey method of research. The primary data for the study was collected from 309 mutual fund investors across different professions in Bangalore City. To capture the dimensions of Illusion of Control Bias and Herding Behaviour, the rating scales from previous studies were used.

To measure the degree of Illusion of Control Bias among investors, a five point likert scale ranging from 'Strongly Agree ' to 'Strongly Disagree' (rating from 1 to 5) was used. Four questions were asked and the respondents were asked to rate depending on how much they agree with the statements. Similarly to measure herding, a five point rating scale from 'Strongly Agree' rated at 1 to 'Strongly Disagree' rated at 5 was used, to understand how the publicly and privately available relevant information is being processed before investment.

2.1 Statistical Techniques Used: The descriptive analysis of the data is summarized using percentages, mean and standard deviation and presented in the form of tables and charts. To find the degree of association between Illusion of Control and Herding Bias a Correlation Analysis was done. The regression equation for the same is estimated to predict the value of the dependent variable based on the independent variable i.e., Herding bias. 


\section{ANALYSIS \& RESULTS}

\subsection{Mean And Standard Deviation Of The Variable Illusion Of Control Bias}

The Table 3.1 shows the statements measuring illusion of control bias. Four questions were asked to respondents to measure their illusion of control. The number of respondents, its mean and standard deviation for each of the statements is shown in the table.

\begin{tabular}{|l|c|c|c|}
\hline \multicolumn{1}{|c|}{ Attributes } & N & Mean & $\begin{array}{c}\text { Std. } \\
\text { Dev. }\end{array}$ \\
\hline $\begin{array}{l}\text { Q1-I believe that I have a good amount of control in picking } \\
\text { the investments that outperform the market }\end{array}$ & 301 & 2.44 & 0.87 \\
\hline $\begin{array}{l}\text { Q2-When returns on my investment increases, it is because of } \\
\text { the control I have exercised over the outcome on my } \\
\text { investment }\end{array}$ & 302 & 2.47 & 0.84 \\
\hline $\begin{array}{l}\text { Q3-I am more likely to win, If I choose the numbers while } \\
\text { purchasing the lottery ticket than using a computer generated } \\
\text { number }\end{array}$ & 299 & 3.13 & 1.07 \\
\hline $\begin{array}{l}\text { Q4-I feel more in control when I roll the dice, while } \\
\text { participating in games of chance that involve dice }\end{array}$ & 300 & 2.93 & 1.09 \\
\hline
\end{tabular}

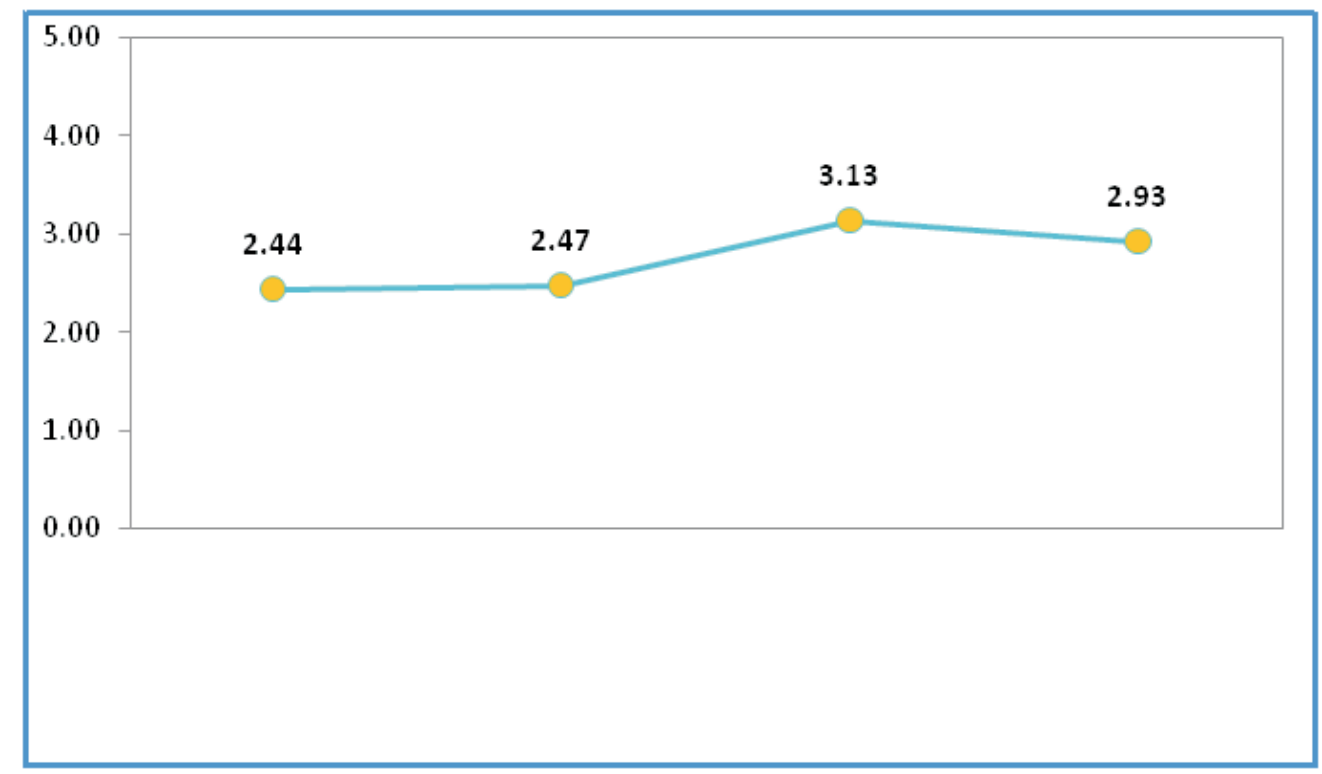

Figure 3.1: Mean of Illusion Of Control Bias 
The mean and standard deviation for the question 1 , is 2.44 and 0.87 . For question 2 , it is 2.47 and 0.75 . For Questions $3 \& \$$, it is 3.13 and $1.07 \& 2.93$ and 1.09 respectively.

Though the mean for all attributes indicate the presence of Illusion of Control Bias, whenit comes to choosing lottery numbers and involving in the game of chance, a higher illusion of control is exhibited .

\section{2: Mean And Standard Deviation Of The Variable Herding Bias.}

Table 3.2 Shows the attributes measuring Herding Bias. Three questions were asked to respondents to measure their herding behaviour. The number of respondents, its mean and standard deviation for each of the statements is described below.

Table 3.2. Opinion on Investment - Herding Behaviour

\begin{tabular}{|l|c|c|c|}
\hline Attributes & N & Mean & $\begin{array}{c}\text { Std. } \\
\text { Dev. }\end{array}$ \\
\hline $\begin{array}{l}\text { Q1-My colleagues and friends are an important source of } \\
\text { information }\end{array}$ & 306 & 2.38 & 0.91 \\
\hline Q2-When I make an investment, I generally follow the trend & 307 & 2.34 & 0.83 \\
\hline $\begin{array}{l}\text { Q3-I consider most of the published economic and political } \\
\text { information when I invest }\end{array}$ & 305 & 2.24 & 0.88 \\
\hline
\end{tabular}

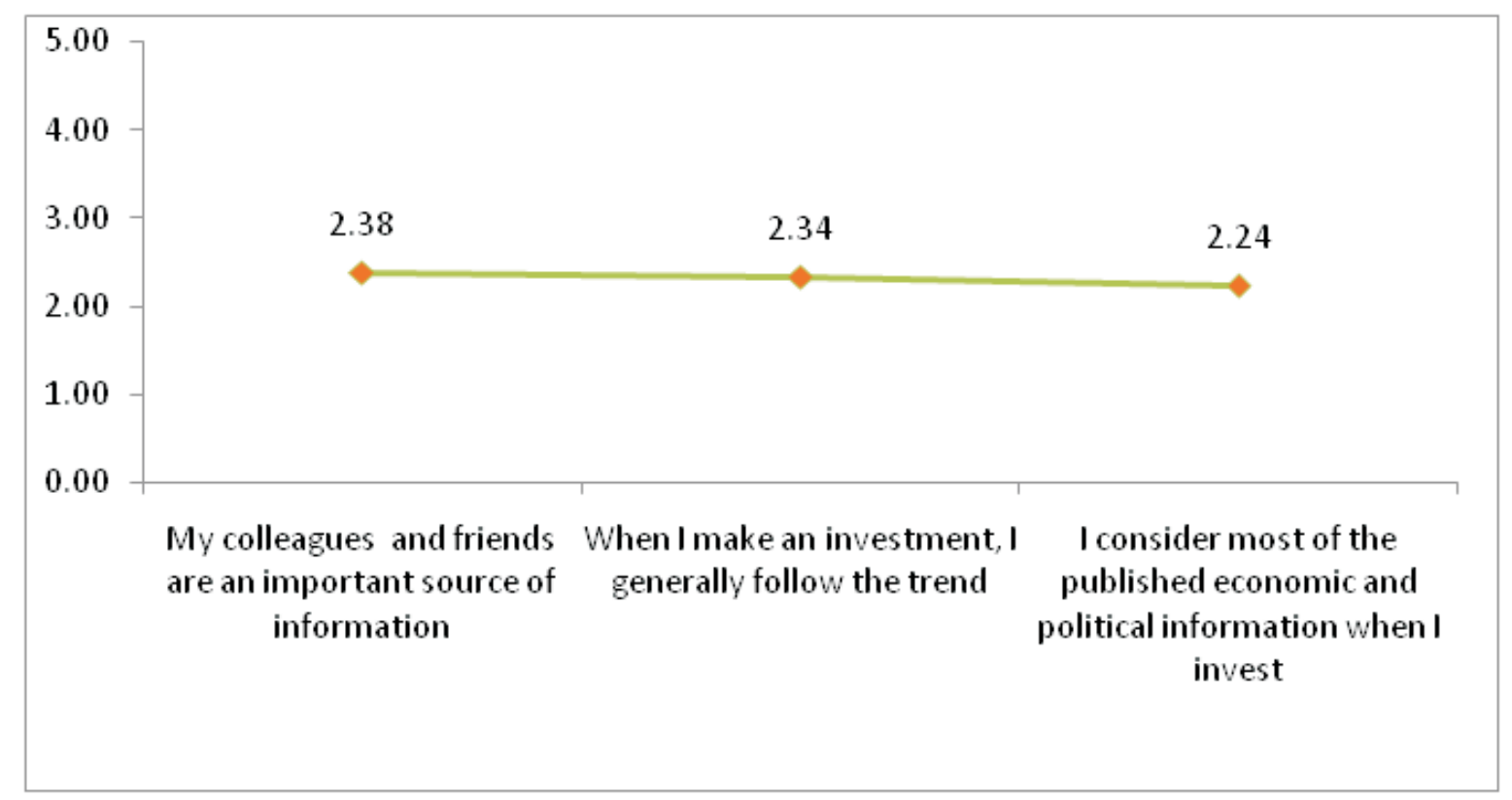

Figure 3.2: Opinion on Investment- Herding Behaviour

The mean and standard deviation for Q1 is 2.38 and 0.91. For Q2, it is 2.34 and 0.83 . and for the third attribute, it is 2.24 and 0.88 . The mean does not show any significant difference for all the three attirbutes. 


\section{3: Correlation Between Biases}

Pearson's correlation ' $r$ ' is calculated to find the degree of association between Illusion of Control Biasand Herding. Table 3.3 shows the correlation between the two biases.

H0: There is no significant relationship between Illusion of Control Bias and Herding Bias

H1: There is a significant relationship between Illusion of Control Bias and Herding Bias

Table 3.3: Correlation Between Biases

\begin{tabular}{|l|l|c|}
\hline \multicolumn{2}{|c|}{ Bias } & \multicolumn{2}{|c|}{$\begin{array}{c}\text { Illusion Of } \\
\text { Control }\end{array}$} \\
\hline \multirow{2}{*}{ Herding } & Pearson Correlation & $.218^{* *}$ \\
\cline { 2 - 3 } & Sig. (1-tailed) & 0.000 \\
\cline { 2 - 3 } & $\mathrm{N}$ & 302 \\
\hline
\end{tabular}

**. Correlation is significant at the 0.01 level (1-tailed).

The above analysis shows a positive association between Illusion of Control and Herding Bias, the ' $r$ ' value is . 0.218 and the sig. value is 0.000 . As the sig. value $<0.01$.the association is statistically significant implying that there is a significant relationship between Illusion of Control and Herding Bias.

\section{4: REGRESSION ANALYSIS}

The statistically significant correlation coefficient, merely indicates that the observed sample data provides ample evidence to reject the null hypothesis. The coefficient of determination ( $\mathrm{r} 2$ ) can be used to more fully interpret ' $r$ '. The coefficient of determination is defined as the percent of variation in the values of dependent variable ( $\mathrm{Y}$ ) that can be explained by the independent variable $(\mathrm{X})$. This technique results in a percent value which makes interpretation much more clearer. To define the pattern of the existing relationship in correlation, the regression analysis is used. A mathematical equation is developed for the line of best fit representing the data. So in the following section, we estimate the regression equation $\mathrm{Y}=\mathrm{a}+\mathrm{b} 1 * \mathrm{X} 1+\mathrm{e}$, to predict the value of the dependent variable (Herding Bias) based on the independent variable (Illusion of Control Bias).

3.4.: Illusion Of Control As A Predictor Of Herding Bias

HO: The independent variable Illusion of Control is not a significant predictor of the dependent variable Herding

H1: The independent variable Illusion of Control is a significant predictor of the dependent variable Herding 
Table 3.4a: Model Summary

\begin{tabular}{|c|c|c|c|c|c|}
\hline $\begin{array}{l}\text { Independent } \\
\text { Variable }\end{array}$ & $\begin{array}{l}\text { Dependent } \\
\text { Variable }\end{array}$ & $\mathbf{R}$ & R Square & $\begin{array}{l}\text { Adj. R } \\
\text { Square }\end{array}$ & \\
\hline Illusion of Control & Herding & 0.218 & 0.048 & 0.045 & 0.587 \\
\hline
\end{tabular}

The Table 3.4.a shows the $\mathrm{R}$ square value of 0.048 , which provides an indication of the explanatory power of the regression model. It is the percentage of variance in the dependent variable explained by the independent variables (predictors). So, 4.8 percentage of variance in Herding is explained by the predictor variable Illusion of Control. The Table 3.4.b ANOVA model, explains whether the variance is significant.

Table 3.4.b: ANOVA

\begin{tabular}{|l|c|c|c|c|c|}
\multicolumn{9}{|c}{ Model } & Sum of Squares & Df & Mean Square & F & Sig. \\
\hline Regression & 5.184 & 1 & 5.184 & 15.030 & 0.000 \\
\hline Residual & 103.478 & 300 & 0.345 & & \\
\hline Total & 108.662 & 301 & & & \\
\hline
\end{tabular}

Predictors: (Constant) Illusion of Control

Dependent Variable: Herding

The ANOVA Model above shows an F value of 15.030 and a sig value of 0.000 . As the sig. value $<0.01$, we reject the null hypothesis and can infer that, the independent variables Illusion of Control is a significant predictor of the dependent variable Herding

\section{Table 3.4c: Coefficients}

\begin{tabular}{|c|c|c|c|c|c|c|}
\hline & & $\mathrm{Co}$ & ents & & & \\
\hline & & Unstandardized & Standar & & & \\
\hline & Model & Coefficients & & & $\mathbf{T}$ & Sig. \\
\hline & & B & Std. Error & Beta & & \\
\hline & (Constant) & 1.801 & 0.137 & & 13.133 & 0.000 \\
\hline 4 & $\begin{array}{l}\text { Illusion of } \\
\text { Control }\end{array}$ & 0.188 & 0.049 & 0.218 & 3.877 & 0.000 \\
\hline
\end{tabular}

Dependent Variable: Herding

The above table 3.4.c. shows the unstandardised and standardized beta coefficient between independent and dependant variable. Unstandardised beta is used to estimate the regression equation. The $\mathrm{y}$-intercept is 1.801 and the slope of the regression line is $\mathrm{b} 1=0.188$. The calculated t-value is 3.877 and the sig. value is for Illusion of Control is 0.000 As the sig. value $<.001$, for illusion of Control we can infer that the independent variable, is a significant predictor of the dependent variable Herding Bias.

Inference: The estimated equation is $\mathrm{Y}=1.801+$ $0.188 * \mathrm{X} 1+$ e. An increase in one unit of independent variable (X1) i.e. Illusion of Control increases the dependent variable Herding 18.8 percentage. Illusion of Control is 
considered as a significant predictor of the dependent variable Herding Bias..

\section{FINDINGS \& CONCLUSION}

The results of the study indicate 1) the presence of Illusion of Control Bias and Herding among Mutual Fund Investors. 2) A positive relationship between Illusion Of Control Bias and Herding and 3) Illusion of Control is a significant predictor of Herding. From the client advisor perspective, an understanding of the psychology and emotions underlying investment decisions, can mutually benefit both the financial advisors and individual investors in formulating their financial goals better and making wise investment decisions. This study is not comprehensive enough to understand the various biases influencing investor decision. The findings of the study increases the scope for further studies on how one bias can lead to the other and their combined influence on herding.

\section{REFERENCES :}

- $\quad$ Avery, C N \& Chavelier, J A 1999, 'Herding Over Career', Economic Letters, Vol.63, pp.327-333

- Beatriz Fernández, T. G.-M. (2001). the role of the interaction between information and behavioral bias in explaining herding. Departments of Financial Economics and Accounting, and Management . valalodid, spain

- $\quad$ Bikhchandani, S \& Sharma, S 2000, 'Herd Behavior in Financial Markets: A Review'. IMF Staff Papers, Vol. 47, No.3, pp.279310.

- $\quad$ De Bondt, W.F.M. \&Thaler 1985, 'Does the stock market Overreactfl', Journal of Finance, Vol.40,pp.793-805.

- $\quad$ Eagly, A H, \&Carli, L L 1981, 'Sex of researchers and sex-typed communications as determinants of sex differences in influence ability: a Meta-Analysis of Social Influence Studies, " Psychology.
Bulletin',Vol.90, No. 1, pp.1-20.

Fama, E F 1965 ' Random Walks in Stock Market Prices. Financial Analysts Journal', Vol. 21 No.5, pp.55-59.

Fellner G 2004, ' Illusion of control as a source of poor diversiflcation: An experimental approach', Journal of Behavioural Finance, Vol.10, No. 9, pg.5557

Hirshleifer, D 2001 'Investor Psychology and Asset Pricing', Journal of Finance 'Vol. 56,pp.1533-1597.

Langer, E. (1975), "The Illusion of Control," Journal of Personality and Social Psychology, Vol.32,pp.311-328.

- $\quad$ Maug, E. \& Naik, N 1996, ' Herding and delegated Portfolio Management'. Working paper(London Business School).

- Megumi S \& Toshino M, 2004 , 'Behavioural Biases of Japanese Institutional Investors, Fund Management and Corporate Governance', Working Paper Series (WIF 04-004) Waseda University, institute of Finance, Japan

Menkhoff et.al 2006, 'The impact of experience on risk taking, overconfidence, and herding of fund managers: Complementary survey evidence', European Economic Review, vol 50, No.7, pp..1753-1762

Nofsinger \& John, R 2001 'The Psychology of Investing', Prentice Hall

Krishnan, M, Lim,S \& Zhou,P 2006,'Analysts Herding Propensity: Theory and evidence from earnings casts, Working paper, http://ssrn.com/abstract=929467.

Taqadus Bashir et al., (2014),Impact Of Cognitive Profile And Information Uncertainty On Herding Behavior Of Investor,IOSR Journal of Business and Management, Volume 16, Issue 1. Ver. V (Feb. 2014), PP 68-74 